\title{
Research on the Design of Park Bench Based on Humanized Concept
}

\author{
Zhi-hui PANG ${ }^{1,2}$, Ming CHEN ${ }^{1,2, a}$, Jian-hua LYU ${ }^{1,2, b, *}$ \\ ${ }^{1}$ Forestry College, Sichuan Agricultural University, Chengdu 611130, China \\ ${ }^{2}$ Key Laboratory of Wood Industry and Furniture Engineering of Sichuan Provincial Colleges and Universities, \\ Sichuan Agricultural University, Chengdu 611130, China \\ achenming@sicau.edu.cn, bljh@sicau.edu.cn \\ *Corresponding author
}

Keywords: City parks, humanized, multi-function, bench.

\begin{abstract}
In this paper, current status of park benches are analyzed, design flaw and function shortages are discussed, and the necessity of safety design and multi-function design are elaborated through analysis of the needs of modern users on park benches. According to humanized design principle, in this paper, the design content of park benches is analyzed and a new park bench design schemes is designed combining its style and function with the actual needs of users to provide new ideas for park bench design.
\end{abstract}

\section{Introduction}

At present, the quantity and quality of parks of a city are important indicators in evaluating a city's influence and habitability[1], and the design of benches plays an important part in overall construction of a park. Currently, the domestic research and design of park bench are still in initial stage, and although some research results are gained, there are still many problems [2]. Embodying humanized design concept in park bench design will improve security and utility significantly. Therefore, it is a must to enhance the research and design of park benches.

\section{Status Analysis of Park Benches}

A park is an open space with green land for frequent recreational activities; it provides a place for daily fitness activities, communication and recreational activities for urban citizens [3].

\subsection{Lacking shading and sheltering facilities}

Through research of data, it is found that there is no rain shelters; majority of the users said that: in sunny days, few people is willing to go to the park due to the strong sunlight as well as possible showers for there is no shelter in the park [4]. Lacking of shading and sheltering makes people may directly influence people's decision on whether go to the park or not, therefore, this is currently an important issue to be solved immediately for park infrastructure construction.

\subsection{Overlook of children use safety}

Among groups in parks, children take the majority, they are always accompanied by their families. Compared with adults, children have more simple thoughts, undeveloped attentiveness, memory and logical thinking, and they always are full of energy and like jumping and frolicking [5]. However, except for special children parks, few parks provide park benches special for children [2]. Benches in ordinary parks are mainly designed according to adults' body sizes and using habits to meet their' needs, with no consideration given to children's safety. 


\subsection{Inadequate numbers of fitness facilities}

With the upsurging of fitness craze, fitness is playing an ever important part in people's daily life. Fitness equipment is the basic equipment for park fitness activities; due to the number of people in parks is increasing and number of part of equipment is limited, each piece of fitness equipment can be occupied in a certain period of time, and people have to wait. Visitors always go to the park alone or with accompany, they talk to each other occasionally[6]; however, both the design and quantity of existing fitness equipment cannot meet the needs.

Through analysis of above mentioned phenomena, it can be seen that the actual needs of people are hardly considered, which leads to poor practicability of benches. Therefore, the benches designer shall think from the perspective of the user to integrate visitors' needs into design and attach importance to the correlation between people and things, so as to realize humanized design.

\section{Humanized Design Principle of Park Benches}

Nowadays, "people oriented" development is emphasized, including development of city parks. As indispensable facilities in city parks, the park benches design shall also follow the humanized concept [7], and follow humanized principle in the design.

\subsection{Functional principle}

With the improvement of people's living standard and quickening of living space, people are looking for more convenience in life, they pay more attention to the multi-functions of benches more than basic functions like seat or lying, for example, relaxing, communication and entertainment purposes. Therefore, in addition to basic functions, designers shall integrate more functions into the benches to enhance bench functions and eliminate visitors' worries, and realize humanized design of park benches[8].

\subsection{Safety principle}

In park bench design, every possible behavior of different group of people shall be considered. Children like frolic, therefore, safety factor must be considered in the design of park bench design; specifically, safety design shall be embodied in structure, form as well as craft to avoid possible safety hazards to bench users, and to embody safety principle in park bench design[9].

\subsection{Diversity principle}

With the constant development of cities in China, the construction of recreational facilities like park is optimizing, and designers are paying more attention to humanized design philosophy. Park visitors can be classified into children and adult groups, and different groups have different expectations on park benches. Designers shall not just imitate traditional and classic design styles in park bench design, and shall have different focuses for different groups at different ages to make sure that park bench design caters to sizes and using habits of users at different ages. Design shall be innovative and in diversiform style to enrich the design styles of park benches[7].

\subsection{Usability principle}

Usability must be considered in park bench design, especially child seats. If usability is ignored in park bench design, complex operation will arouse feeling of resistance of people, especially children, or they may even refuse to use the bench. Therefore, usability of park benches is of great importance. To enhance the usability of park benches, not only users' safety, easy operation shall also be paid attention to. Easy-to-use park benches are likely to arouse people's interest, and facilitate communication between benches and users and meet the physiological and emotional needs of people[5].

Park bench plays an important role in park construction, the humanized design of benches cannot only embody the "people-oriented" design principle, but also integrates visitors' needs to improve 
citizens' quality of life. Therefore, without deviating from park theme, benches design shall integrate actual needs of visitors as well as the surrounding environment, to embody humanized design concept. This kind of design cannot only tackle the common problems the park infrastructures are facing and bring comfort to visitors but also utilize park space fully and optimize construction of overall facilities in the park.

\section{Design Examples}

In order to create a better park environment, the design shall be improved from perspective of functions and safety while keep advantages of current benches for a more humanized park bench design.

\subsection{Design of park bench for body building and sheltering \& shading}

Although the sports facilities in parks in China is taking shape and have seen certain development and improvement in construction and management, there still is space overall development[10], especially, in terms of quantity of fitness equipment and innovation. Design integrating fitness function and sheltering function can not only meet more visitors' demand, but also enhance parks facilities' creativeness.

The bench is mainly composed of shelter and the seat (Figure 1). The shelter is fixed on the seat through slot with two independent parts connected by batten, i.e. the left part and right part; a universal joint yoke is respectively set on the left bottom of the left shelter and right bottom of right shelter to adjust the status of the shelter.

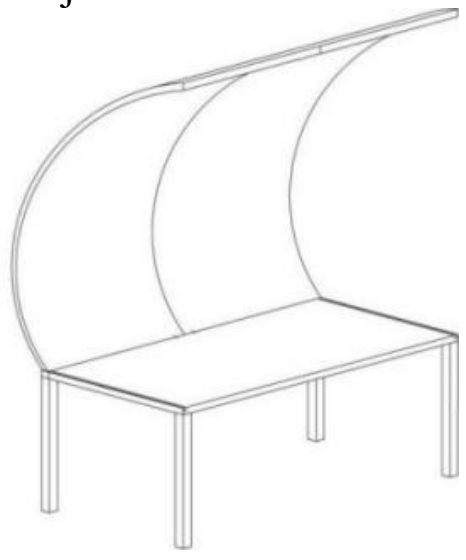

Figure 1 Shelter Functioning as Canopy

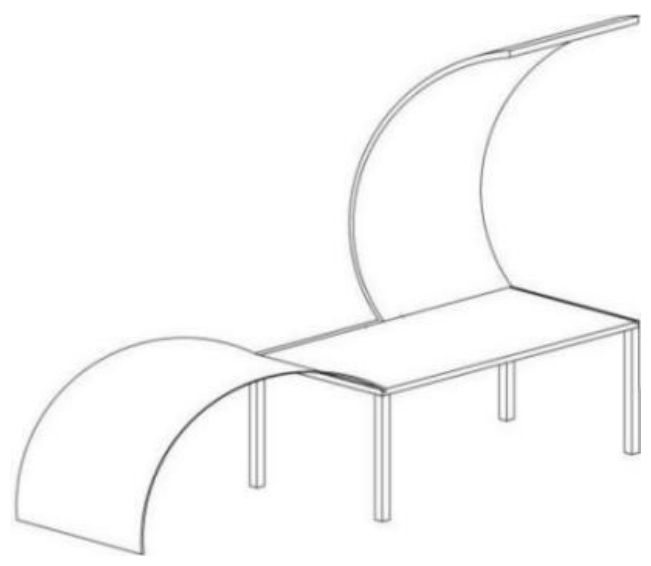

Figure 2 Shelter Functioning as Fitness Equipment

Slots are set on both sides of the seat; when the batten in the middle is removed, the shelter can be adjusted through the universal joints to form fitness equipment with the shelter bottom fixed in the slot at the edge of the seat. On the fitness equipment formed by the shelter, people can do excise with back lean against the arc or do leg pressing (Figure 2); Conversion from shelter to fitness equipment is easy to operation with high security, and visitors can adjust according to their needs.

The bench integrating fitness function and sheltering function can not only solve the shortage of fitness equipment, but also meet the fitness demands of more visitors; on the other hand, the shelter can not only function as a shelter and shed for visitors, it can also protect the bench from rain and sun to lengthen the service life of the bench. The design solved the existing problems in park facilities construction, and embodied the humanized concept.

\subsection{Design of park bench for different groups and sheltering \& shading}

Based on safety and diversity principle, humanized benches for different groups can not only meet people's requirements on resting, but also facilitate children use.

The park bench cannot only be used as ordinary benches, and it also has sheltering function and child seat function. The bench is mainly composed of four parts, i.e. ordinary seat, children seat, back and shelter. The bench is divided into two parts, i.e. ordinary seat and children seat. A rotation axis is set at the connection of the supporting leg of children seat and bench transom; the supporting leg is 
connected with the axis, and the seat can be lowered by pulling the children seat; this design helps children to seat on their own to avoid possible safety accident (Figure 1, Figure 2).

In addition, the foldable shelter is set on the back with two layers, and pulleys are provided on the bottom edge of the shelter to realize spreading of the two layers of shelter through sliding on slideway. Foldable shelter design can realize shelter coverage adjustment according to people needs (Figure1, Figure 2).

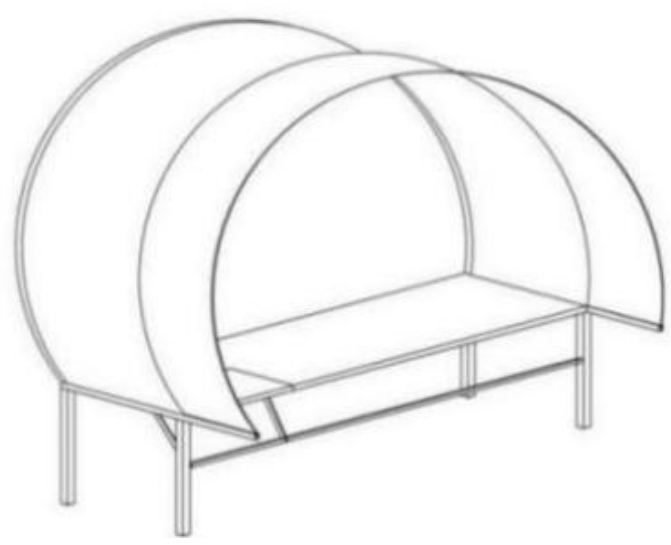

Figure 1 Bench with Fully Expanded Shelter

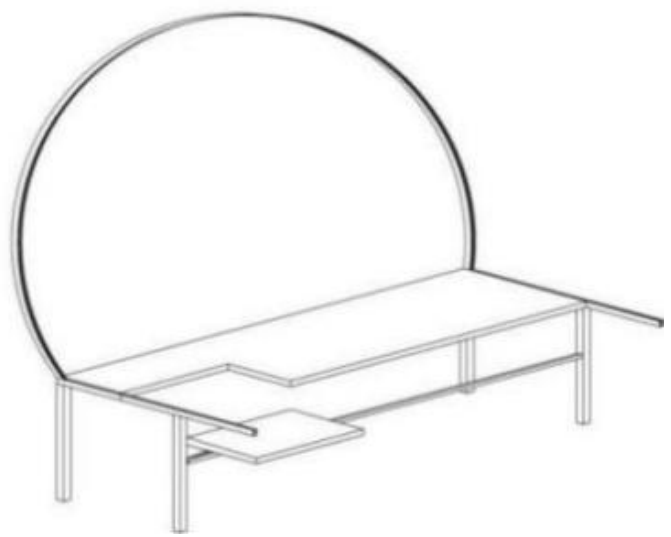

Figure 2 Bench with Child Seat

Park bench designed with child seat eliminates the potential safety hazard when children use the bench on their own. Design of child seat cannot only enhance children's independence, but also meet needs of different groups. This design embodies the humanized concept characteristics.

\section{Conclusion}

Park is the outdoor place for citizen recreational activities and communication[11]. Park bench is one of the most important parts in park landscape, and it's becoming more important; its design and arrangement can directly impact physiological and mental activities[12]. Based on "people-first" principle, considering of visitors' actual needs in bench design can not only solve the existing problem in park facility, promote multi-direction development of park, but also meet visitors' needs and realize sustainable development of park. Humanized design is of great importance to future design of park facilities in China.

\section{Acknowledgments}

This project is supported by Key Laboratory of Wood Industry and Furniture Engineering of Sichuan Provincial Colleges and Universities.

\section{References}

[1] Liu Changfu, Li Xiaoma, Han Dong. Accessibility Analysis of Urban Parks: Methods and Key Issues[J]. Acta Ecologica Sinica,2010, 30(19):5381 5390.

[2] Xiao Fei. The Research of Park Furniture Design[D]. Fujian Agriculture and Forestry University,2013.

[3] Lv Hong. Research on the Relationship between Recreation Activity and Space of the City Park[D]. Shandong Agricultural University,2013.

[4] Liu Wenli, Guo Yongshan, Qiu Yanqing. Investigation of Utilization Status of the Qijiang Park by POE Research Method[J]. Guangdong Landscape Architecture Magazine, 2007, 29(2):68 70.

[5] Luo Bijuan. Humanized Design of Children Product[J]. Packaging Engineering, 2006, 27(1):213 217. 
[6] Fan Wen,Da Liangjun, Zhang Kaixuan. Research on the Use Characteristics of Physical Fitness in City Park - A Case Study in Shanghai[J]. Modern Urban Research, 2015, (10):94 99.

[7] Ye Yumei, Huang Lingyu, Xiong Shufeng. Investigation and Study on Design of Xiamen Park Benches[J]. Journal of Hebei North University (Natural Science Edition), 2013, (6):51 54.

[8]Zong Yan. Humanized Design Principle of Rest Chairs in Public Leisure Space[J]. Journal of Jilin Jianzhu University, 2015, (4).

[9] Yu Fei. Discussion on User-friendly Policy in the Design of Public Facilities[J]. Packaging Engineering, 2011, (12):134 138.

[10] Wu Xiaocai. Research on Construction, Operation and Management of Chengdu Sports Park in the Context of Nationwide Fitness Programs[D]. Chengdu Sport Institute, 2013.

[11] Zhao Qi. Research on Humanized Design of the City Parks[D]. Hebei University of Science and Technology, 2015.

[12] Tang Huihua, Gao Fengjuan. Investigation and Research of Park Bench Design and Arrangement - A Case Study in Liandu District in Lishui City[J]. Anhui Agricultural Science Bulletin, 2013, (9):134 135. 